Manuscript Number:

Title: Numerical studies on the entire debonding propagation process of the FRP strip externally bonded to the concrete substrate

Article Type: Research Paper

Keywords: FRP strips; Concrete structures; Closed-form solutions; Loaddisplacement responses

Corresponding Author: Dr. Wei Sun, Ph.D.

Corresponding Author's Institution: Lanzhou University

First Author: Wei Sun, Ph.D.

Order of Authors: Wei Sun, Ph.D.; Xu Peng; Yang Yu

Abstract: Debonding of the FRP strip from the concrete substrate is an importance issue in strengthening concrete structures. While a great number of papers have been published on the interfacial behavior of the FRP-concrete bond, few closed-form solutions are available to well predict the load-displacement responses for the FRP strip bonded to the concrete substrate. This paper studies the full-range behavior of the FRP strip debonding from the concrete substrate by using the predictions of FE simulations which show good correlation with experimental results. Then, expressions are derived to describe the load-displacement responses for different loading stages. The impacts of the strip width, the bond length, the thickness and elastic modulus of the FRP strip on the proposed solutions have also been discussed. Analytical solutions show good accordance with experimental results and numerical predictions, indicating its reliability on predicting the interfacial behavior for the strip with various properties.

Suggested Reviewers: James Jirsa

University of Texas at Austin

jirsalutexas.edu

Kenneth Liechti

University of Texas at Austin

kml@mail.utexas.edu

Scott Smith

Southern Cross University

scott.smithescu.edu. au

Paul Robinsion

Imperial College London

p.robinsioneimperial.ac.uk

Jin-Guang Teng

The Hong Kong Polytechnic University

cejgtengepolyu.edu.hk 
Highlights

\section{Highlight}

$>\quad$ Numerical models have been developed to study the entire debonding propagation process of the FRP strip bonded to the concrete substrate.

Based on the numerical predictions, easy and robust closed-form expressions have been proposed to describe the load-displacement responses which service as a good reference for the design of the FRP strengthened concrete structures.

$>$ Both numerical predictions and analytical solutions show good accordance with experimental results, indicating their reliability. 


\title{
Numerical studies on the entire debonding propagation process of the FRP strip externally bonded to the concrete substrate
}

\author{
Wei Sun*, Xu Peng, Yang Yu \\ Key Laboratory of Ministry of Education for Mechanics on Western Disaster and Environment, \\ School of Civil Engineering and Mechanics, Lanzhou University, Lanzhou 730000, China
}

\begin{abstract}
Debonding of the FRP strip from the concrete substrate is an importance issue in strengthening concrete structures. While a great number of papers have been published on the interfacial behavior of the FRP-concrete bond, few closed-form solutions are available to well predict the load-displacement responses for the FRP strip bonded to the concrete substrate. This paper studies the full-range behavior of the FRP strip debonding from the concrete substrate by using the predictions of FE simulations which show good correlation with experimental results. Then, expressions are derived to describe the loaddisplacement responses for different loading stages. The impacts of the strip width, the bond length, the thickness and elastic modulus of the FRP strip on the proposed solutions have also been discussed. Analytical solutions show good accordance with experimental results and numerical predictions, indicating its reliability on predicting the interfacial behavior for the strip with various properties. Keywords: FRP strips; Concrete structures; Closed-form solutions; Load-displacement responses
\end{abstract}


Over the past decade, the usage of Fiber Reinforced Polymers (FRP) in rehabilitation of concrete structures has progressively increased because of its light-weight, high strength, nonmagnetic properties, high corrosion resistance, and ease of installation in the field [1-14]. Typically, FRP strips are bonded to the concrete substrate using epoxy resin with fibers oriented in the direction needing additional tensile strength. A crucial importance of this strengthening method is the performance of the FRP-concrete bond [15-36]. While a great number of studies have been conducted on the interfacial behavior of the FRPconcrete bond, few are capable of predicting the entire debonding propagation process. For the economic and safe design of the FRP strengthened concrete structures, a sound understanding of the full-range behavior of the FRP strip debonding from the concrete substrate needs to be developed.

Debonding generally starts at a major crack where the stress concentrates. It then propagates along the FRP-concrete interface towards the end of the FRP strip at which the strip completely peels off. The local debonding accompanied with the relative slip between the FRP strip and the concrete substrate can be described as bond stress-slip relations. Based on the bond stress-slip relations, numerical models and analytical solutions can be developed to describe the full-range behavior of the interfacial bond for different loading stages. Pull tests have been conducted to study the nonlinear behavior of the interfacial bond [15-26]. A few closely spaced strain gauges at the centerline of the long effective load-transfer length have been used to determine the bond stress-slip relations [17-21]. In fact, it is hard to capture the debonding process with a few axially arranged strain gauges because unpredictable cracks in concrete cause the considerable and irregular fluctuations of the axial strain measurements. Instead, the nonlinear debonding process can be more reliably obtained from the direct load and displacement measurements at the end of the FRP strip [22-26]. Finite element (FE) models are also developed to provide a convenient 
alternative for the study of the interfacial bond [27-33]. Based on the mesco-scale FE simulations, expressions have been developed to describe the bond stress-slip relations [27-28]. Although those expressions have been widely accepted to model the FRP-concrete bond [34-36], they are unable to describe the debonding propagation process. It would be much easier to obtain the bond behavior from closed-form solutions than from FE simulations. In particularly, $1 \mathrm{~mm}$ or smaller elements have to be used for addressing the size sensitivity problem [29-33]. Yuan et al. [37] have developed analytical solutions to predict the load-displacement responses for the FRP strip bonded to the concrete substrate. The load-displacement curve is linear elastic until it reaches the maximum shear stress of the interfacial increase of the slip. When the bond strength has been developed, debonding occurs and propagates towards the end of the strip. A descending curve initiates at the remained bond length which fails to develop the bond strength. The curve terminates at the ultimate strip displacement as the strip has completely peeled off. The accuracy of those solutions highly depends on the local bond stress-slip relations which can be obtained from either available bond models or experimental measurements. Similarly, Pan et al. [38] have developed closed-form solutions from a simplified bond stress-slip model with a linear ascending part and an exponential softening part. Those solutions [37-38] have been validated with a few experimental results, though the reliability of the solutions for the strip with various strip properties, i.e. various widths, thicknesses, bond lengths and elastic modulus, has not been fully studied.

In this paper, a recently proposed bond model [39] has been used in FE simulations to study the entire debonding process of the FRP strip bonded to the concrete substrate. The predictions obtained from FE simulations are used to determine the effective bond length, the bond strength and its corresponding strip 

describe the load-displacement responses. Those expressions are validated by extensively experimental results obtained from the specimens with various strip properties. The authors believe this study fulfills at least two important functions: (a) it provides a numerical method to study the entire debonding propagation process of the FRP strip bonded to the concrete substrate; and (b) it provides easy and robust solutions to describe the load-displacement responses which service as a good reference for the design of the FRP strengthened concrete structures.

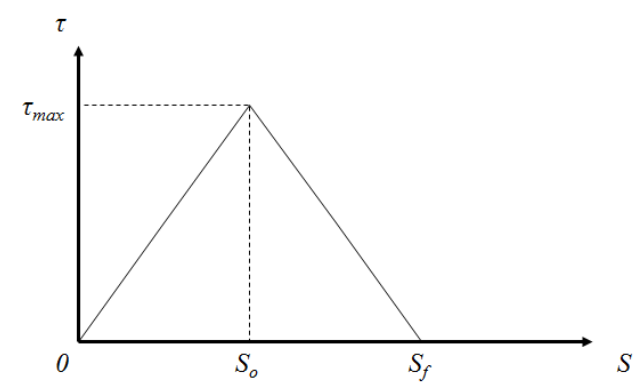

Fig. 1. The bilinear bond stress-slip model. 


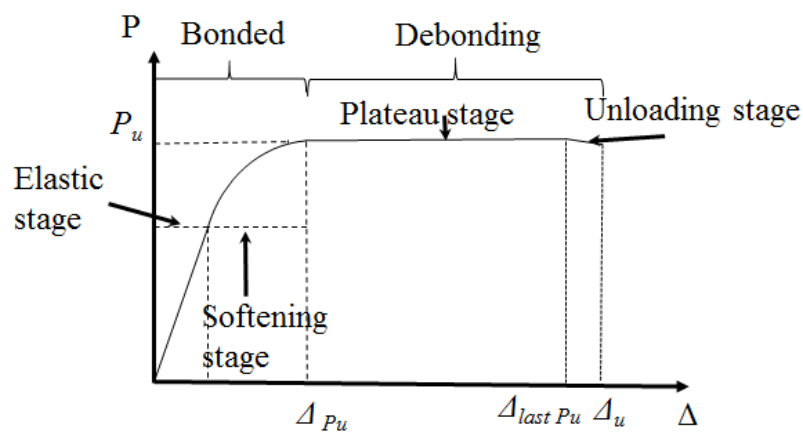

(a)

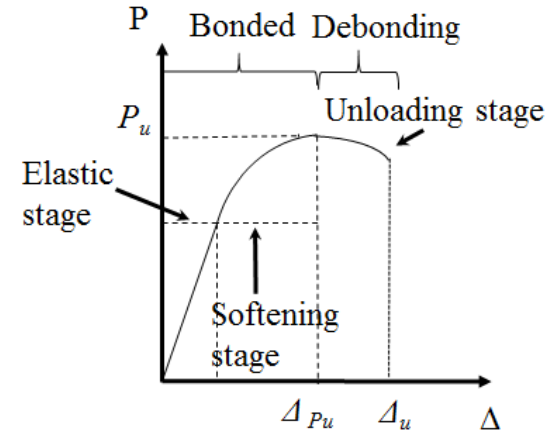

(b)

Fig. 2. Typical load-displacement responses for the strip with (a) an adequate bond length $\left(l_{f} \geq l_{e}\right)$ and (b) an inadequate bond length $\left(l_{f}<l_{e}\right)$.

$$
\begin{aligned}
& \tau=\left\{\begin{array}{cc}
\left(\tau_{m} / s_{0}\right) s & s \leq s_{0} \\
\tau_{m}\left(s_{f}-s\right) /\left(s_{f}-s_{0}\right) & s>s_{0}
\end{array}\right. \\
& \tau_{m}=1.35+0.25 \beta_{w} f_{t}+0.62 f_{t} \\
& s_{0}=0.016-0.0046 \beta_{w} f_{t}+0.11 \beta_{w} \\
& s_{f}=-0.06+\left(0.88-0.23 \beta_{w}^{2}\right) f_{t}^{-0.5} \beta_{w}^{0.5}
\end{aligned}
$$

in which

$$
\begin{aligned}
& \beta_{w}=\sqrt{\frac{1.9-b_{f} / b_{c}}{0.9+b_{f} / b_{c}}} \\
& f_{t}=0.62 \sqrt{f_{c}^{\prime}}
\end{aligned}
$$

Where

$f_{t}$ is the concrete tensile strength;

$f_{c}^{\prime}$ is the cylinder compressive strength of concrete;

$\beta_{w}$ is the width factor;

$b_{c}$ is the prism width;

$b_{f}$ is the strip width.

Previous studies [37-39] indicate that the effective bond length $l_{e}$ has a great impact on the loaddisplacement responses. With an inadequate bond length, i.e. the bond length $l_{f}$ shorter than the 
effective bond length $l_{e}$, the bond strength increases along with the increase of bond length. For the strip with an adequate bond length, a further increase of the bond length beyond the effective bond length produces few increases on the bond strength but improves the ductility of the debonding process.

The bond strength $P_{u}$ of the FRP-concrete bond obtained from an adequate bond length can be mathematically described by Eq. (7) [20, 24]:

$$
P_{u}=b_{f} \sqrt{2 E_{f} t_{f} G}
$$

Where

$E_{f}$ is the elastic modulus of the FRP strip;

$t_{f}$ is the thickness of the FRP strip;

The interfacial fracture energy $G$ obtained from Fig.1 can be described by the following expressions:

$$
G= \begin{cases}\tau s / 2 & s \leq s_{0} \\ \left(s \tau_{m}+\tau s-s_{0} \tau\right) / 2 & s>s_{0}\end{cases}
$$

Assuming the displacement $(\Delta)$ of the FRP strip with an adequate bond length is equal to the interfacial slip $(s)$, it is reasonable before the debonding initiation [37]. Then, the total displacement is the sum of the displacements at the debonding and debonded area. The load-displacement responses in the elastic stage $\left(\Delta \leq s_{0}\right)$ and the softening stage $\left(s_{0} \leq \Delta \leq s_{f}\right)$ as shown in Fig. 2 (a) is therefore described by Eq. (9):

$$
P=\left\{\begin{array}{cl}
b_{f} \sqrt{E_{f} t_{f} \tau \Delta} & \Delta \leq s_{0} \\
b_{f} \sqrt{E_{f} t_{f}\left(\Delta \tau_{m}+\tau \Delta-s_{0} \tau\right)} & s_{0}<\Delta \leq s_{f}
\end{array}\right.
$$

Then, the bond strength can also be described by Eq. (10):

$$
P_{u}= \begin{cases}b_{f} \sqrt{E_{f} t_{f} \tau_{m} s_{f}} & l_{f} \geq l_{e} \\ \beta_{l} b_{f} \sqrt{E_{f} t_{f} \tau_{m} s_{f}} & l_{f}<l_{e}\end{cases}
$$

The solutions to determine the effective bond length $l_{e}$ and the bond length factor $\beta_{l}$ will be provided in the following sections. The following sections also provide the solutions for the displacement $\Delta_{\text {last } P_{u}}$ at the last $P_{u}$ and the ultimate strip displacement $\Delta_{u}$ to describe the entire debonding 
propagation process. As shown in Fig. 2 (b), no plateau stage can be developed for the strip with an inadequate bond length $l_{f} \leq l_{e}$. Unloading responses show up right after the bond strength has been developed. In the following sections, the solutions will also be provided to determine the loaddisplacement responses for the strip with an inadequate bond length.

The numerical studies on the load-displacement responses have been done by using the commercial FE package ANSYS. Based on the published research [28-32, 40], FRP strips have been modeled by two-node truss elements (Link 8). The FRP elements have been connected on the rigid bases by using a series of two-node nonlinear spring elements (Combin 39) with three degrees of freedom translations in the nodal $\mathrm{x}, \mathrm{y}$ and $\mathrm{z}$ direction for each node [41]. The material model used for the FRP strip is linear elastic with an effective modulus of elasticity. Since the failure mode is expected to peel the FRP strip off, no rupture point has been defined. As shown in Fig. 3, FRP nodes connect to a series of $0.01 \mathrm{~mm}$ nonlinear springs on the rigid bases representing the concrete substrate. Nonlinear force-elongation

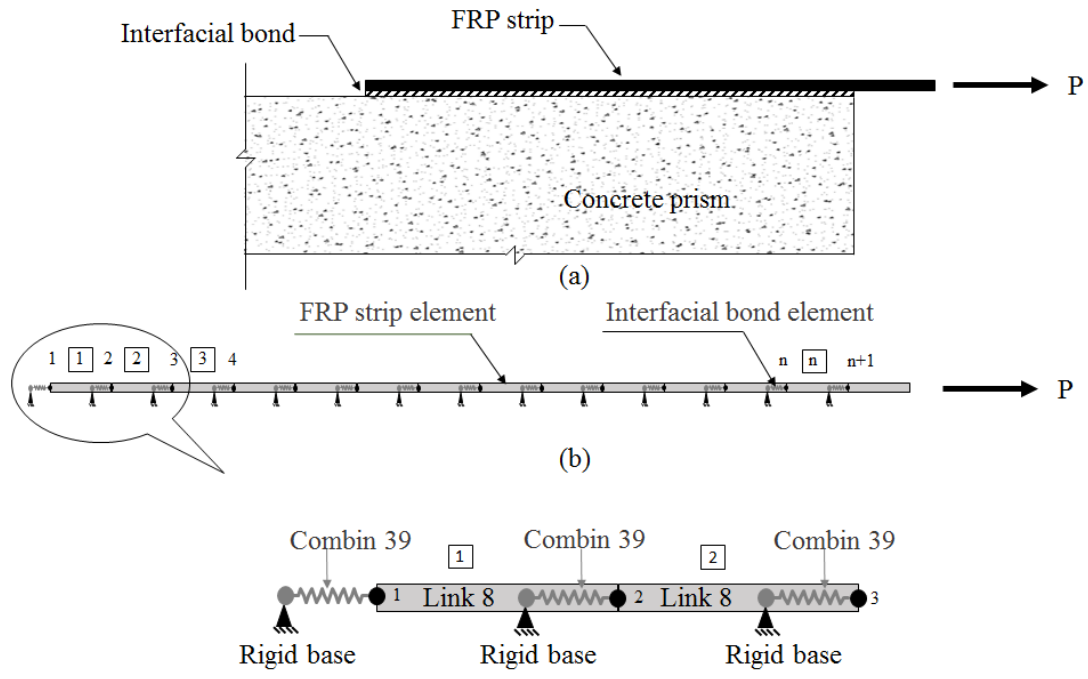

(c)

Fig. 3. Pull tests: (a) FRP strip bonded to the concrete substrate, (b) modelling FRP and interfacial bond with equivalent linear and nonlinear springs, respectively, and (c) details of FRP and interfacial springs. 

in Eq. (1)-(6). Constrains have been applied in the XY plane to prevent any movement in the $\mathrm{Z}$ direction. The tensile load has been directly applied on the last FRP node of the right-hand side.

\section{Verification of the proposed FE model}

Specimen CNW-150-1\&2 reported in the literature [42] have been used to evaluate the proposed FE model. In the selected tests, FRP strips with dimensions of $0.393\left(t_{f}\right) \times 150\left(b_{f}\right) \times 250\left(l_{f}\right)$ mm have been bonded to 200-mm-wide concrete prisms. The value of $f_{c}^{\prime}$ and $E_{f}$ are $44.1 \mathrm{MPa}$ and $227 \mathrm{GPa}$, respectively. Furthermore, four simulations using the $0.1,1,5$ and $10 \mathrm{~mm}$ FRP elements have been conducted to study the sensitivity of element size.

Comparisons between experimental results and FE predictions have been conducted in terms of the load-displacement shape, the bond strength $P_{u}$ and the ultimate strip displacement $\Delta_{u}$. The bond strength mentioned in this paper is the load at the debonding initiation, and the ultimate strip displacement is the displacement at the debonding failure. As shown in Fig. 4 (a), all simulations agree reasonably well with experimental results in terms of the load-displacement shape, the bond strength and the ultimate strip displacement. The simulated load-displacement curves are stiffer as the element size increases. Few differences are observed from the simulations using $0.1,1$ and $5 \mathrm{~mm}$ mesh. This observation suggests that the size sensitivity problem has been effectively addressed for the simulations using the $5 \mathrm{~mm}$ or smaller mesh. The bond strengths obtained from the three simulations are around $50.22 \mathrm{kN}$ which is $97 \%$ and $98 \%$ of the measured values, and the predicted ultimate strip displacements (around $0.78 \mathrm{~mm}$ ) is $91 \%$ and $97 \%$ of the experimental values. As shown in Fig. 4 (b), the proposed model also produces predictions in close agreement with the comparable ones obtained from the 3D FE model [39], further 

been used for modelling the FRP strip in the following simulations.

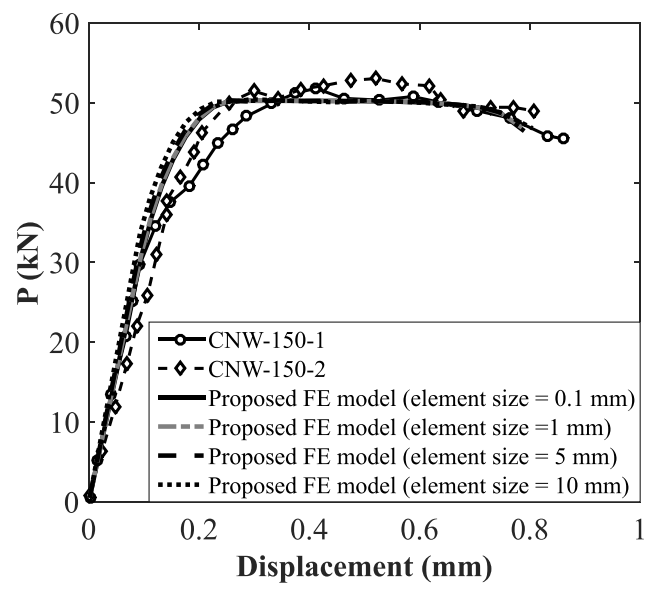

(a)

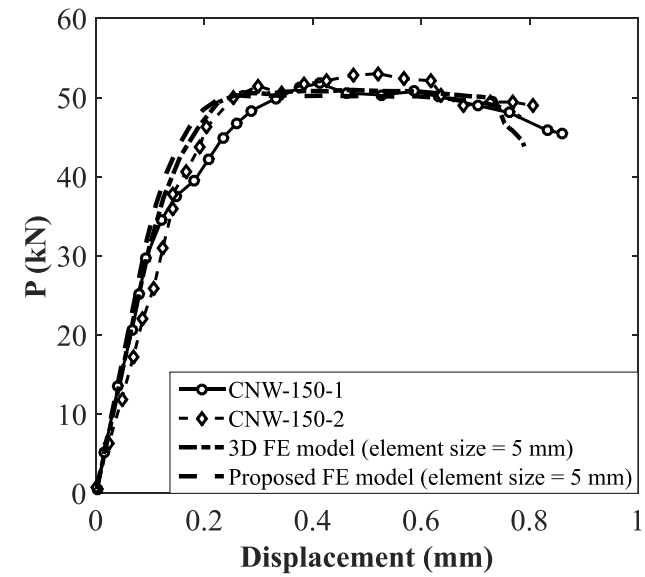

(b)

Fig. 4. Numerical and experimental load-displacement responses of specimen CNW-150-1\&2 [42]: (a) FE predicted load-displacement responses using various element sizes; (b) comparisons between the 3D FE model and the proposed 2D FE model.

\section{Effective bond length based on FE results}

The effective bond length $l_{e}$ is the length beyond which a further increase of the bond length does not increase the bond strength but improves the debonding ductility. Fig. 5 (a) shows the numerical loaddisplacement responses based on specimen $\mathrm{CNW}-150-1 \& 2$. The four points marked on the curve represent the stages at the softening initiation (Point A), the debonding initiation (Point B), the unloading initiation (Point C), and the debonding failure (Point D). As shown in Fig. 5 (a), the applied load does not increase as the strip displacement further increases after Point B. The debonding load at Point B therefore is defined as the bond strength in this study. Fig. 5 (b) shows the bond strength versus bond length responses for ten simulations in which all parameters are the same as specimen $\mathrm{CNW}-150-1 \& 2$ except the bond length varying from 10 to $400 \mathrm{~mm}$, i.e $l_{f}=10,20,40,80,120,130,140,150,250$ and $400 \mathrm{~mm}$. The effective bond length obtained from Fig. 5 (b) is $130 \mathrm{~mm}$ on which $93 \%$ of the bond 
strength, as the shadow area shown in Fig. 5 (c), is developed at the debonding initiation (Point B). Fig.

5 (d) illustrates percentage of the bond strength developed on the effective bond length for a random point at the plateaus stage (Segment BC). At this stage, 93\% of the bond strength is continually developed on the effective bond length. Then, the debonding propagation reaches the bond length which develops the last bond strength (Point C). As shown in Fig. 5 (e), the bond length is equal to $110 \%$ of the effective bond length. The strip completely peels off at $93 \%$ of the bond strength (Point D) as shown in Fig. 5 (f). This observation proves the plateau and the unloading stage after the debonding initiation. At those two stages, a remained bond length less than $110 \%$ of the effective bond length fails to develop the bond strength. Instable results can be produced as the applied load is less than $93 \%$ of the bond strength, which therefore is used in the following sections to determine the ultimate strip displacement.

Previous studies $[15,20,43-47]$ have isolated $f_{c}^{\prime}, E_{f}$ and $t_{f}$ as the three major factors on determining the effective bond length. More complicate expressions consider the impacts of not only the three major factors but also the strip width for determining the effective bond length [28, 37]. Fig 6 shows the impacts of the four factors on the effective bond length. For the simulations plotted in Fig. 6, all parameters are the same as specimen CNW-150-1\&2 except the strip width varying from 75 to $200 \mathrm{~mm}$ as shown in Fig. 6 (a), the strip thickness changing from 0.2 to $0.8 \mathrm{~mm}$ as shown in Fig. 6 (b), the strip modulus ranging from 50 to $300 \mathrm{GPa}$ as shown in Fig. 6 (c) and the concrete strength increasing from 15 to $80 \mathrm{MPa}$ as shown in Fig. 6 (d). Based on the numerical predictions as shown in Fig.6 (a)-(d), the strip width has very limited impacts on the effective bond length. Instead, the effective bond length can be described by the function of $t_{f}^{0.5}, E_{f}^{0.5}$ and $f_{c}^{\prime-0.29}$. Fig. 6 (e) shows the best fit regression line which can be described by Eq. (11)

$$
l_{e}=1.3 \sqrt{\frac{E_{f} t_{f}}{\left(f_{c}^{\prime}\right)^{0.58}}}
$$




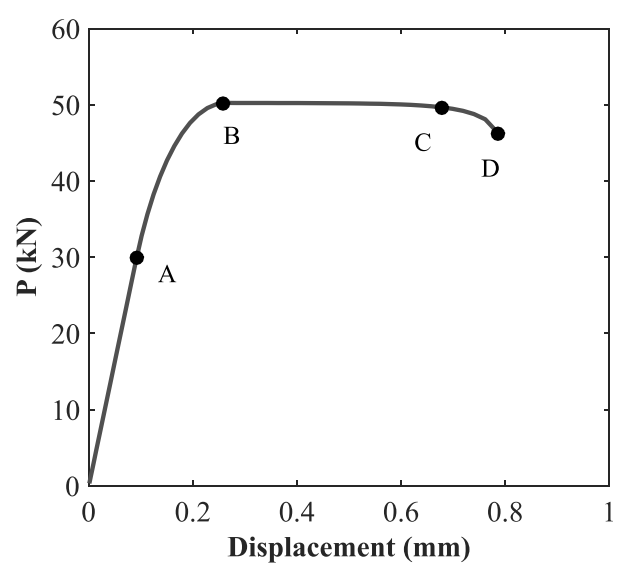

(a)

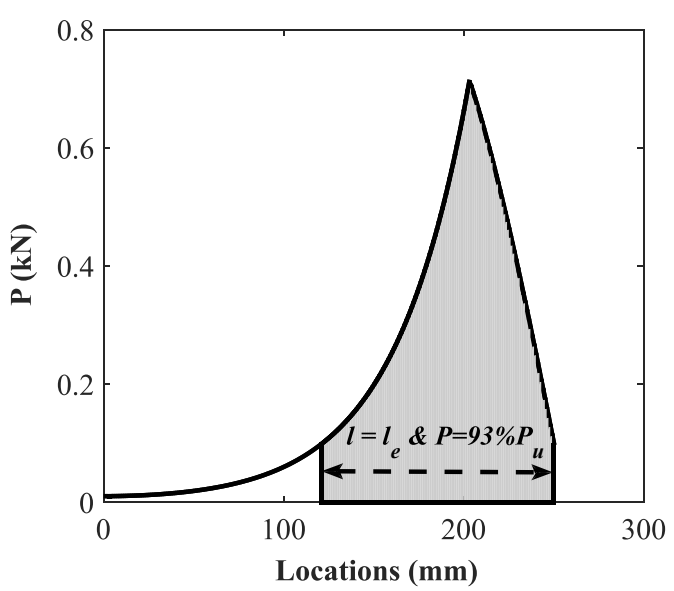

(c)

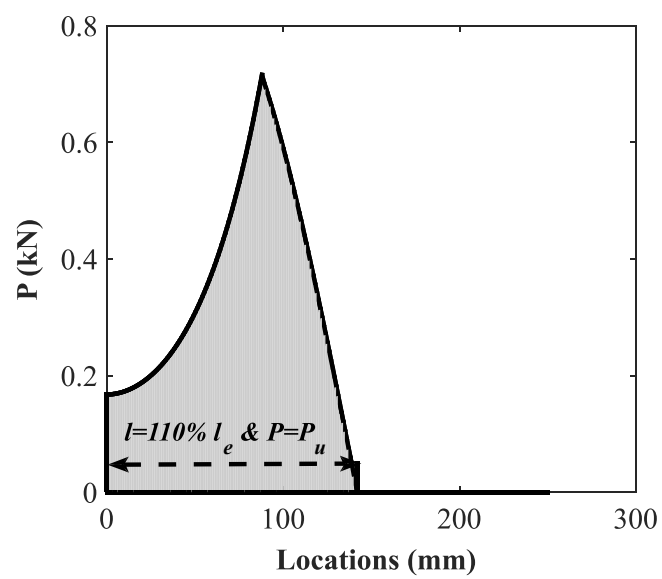

(e)

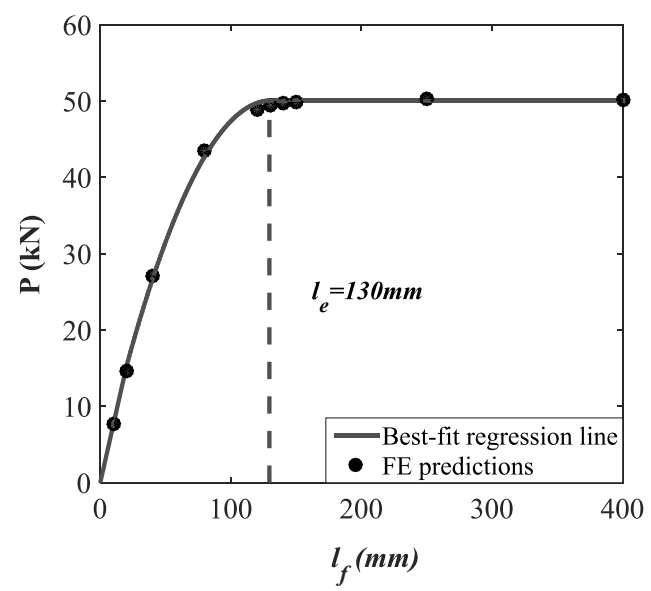

(b)

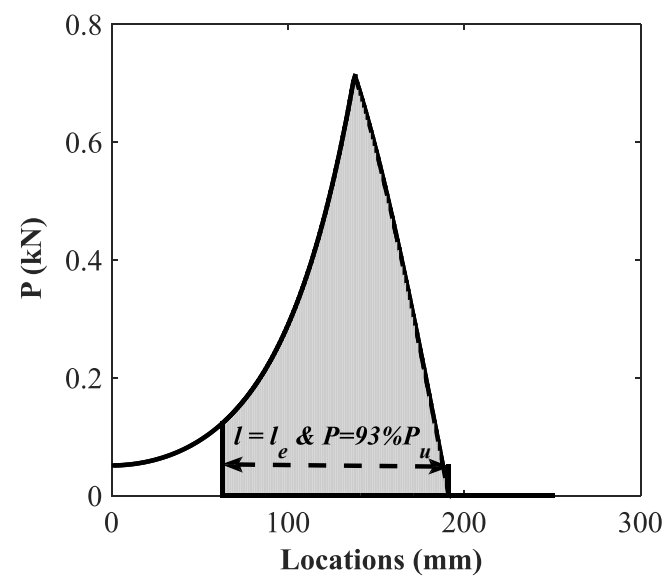

(d)

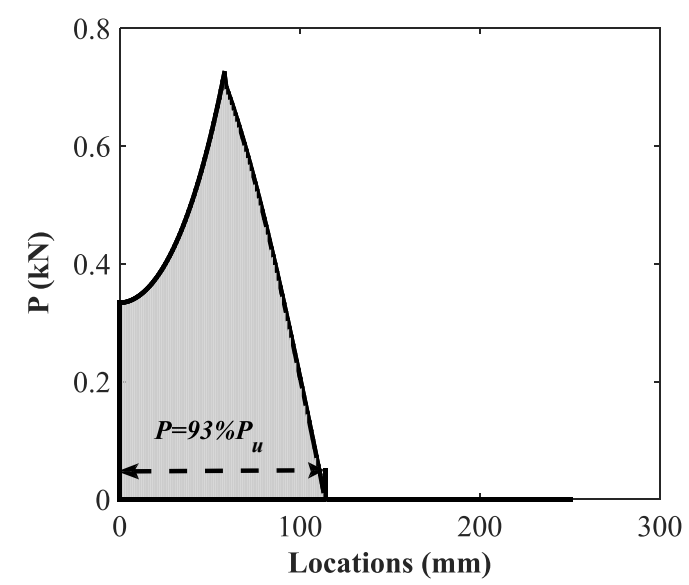

(f)

Fig. 5. Analysis of the bond length: (a) numerical load-displacment responses based on specimen CNW-1501\&2; (b) bond strength versus bond length responses for 150-mm-wide strips; (c) percentage of the bond strength developed on the effective bond length at the debonding initation (Point B); (d) percentage of the bond strength developed on the effective bond length during the debonding propagation (Segment BC); (e) percentage of the effective bond length that develops the last bond strength (Point C); (e) percentage of the bond strength at the debonding failure (Point D). 


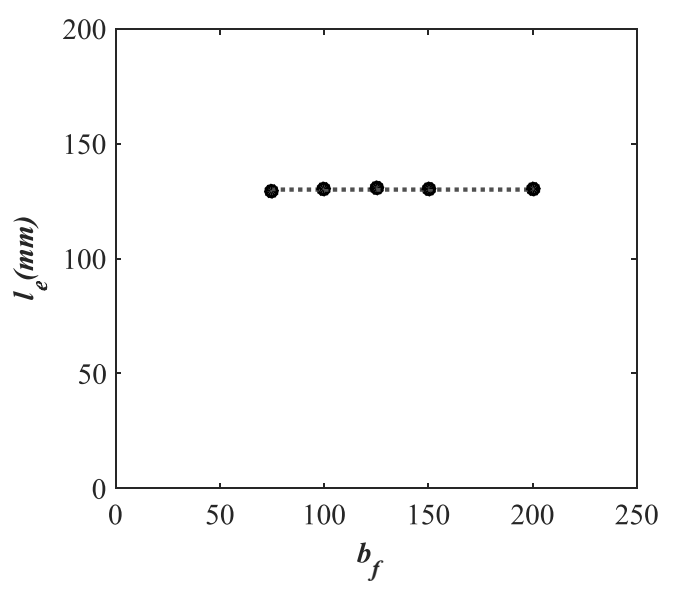

(a)

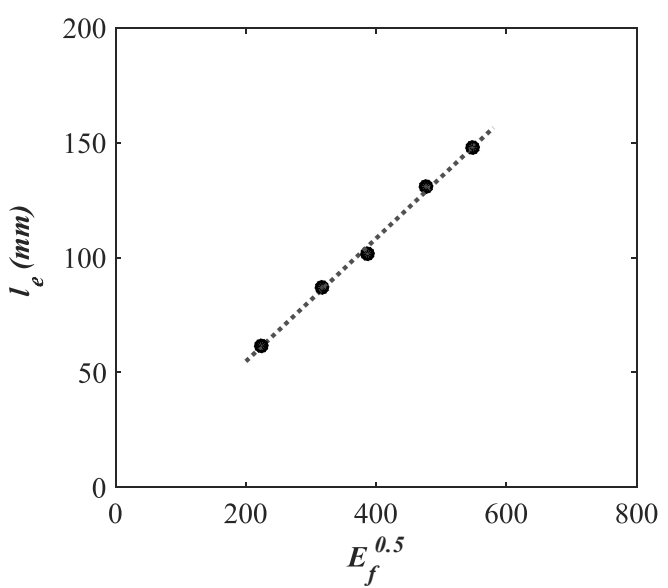

(c)

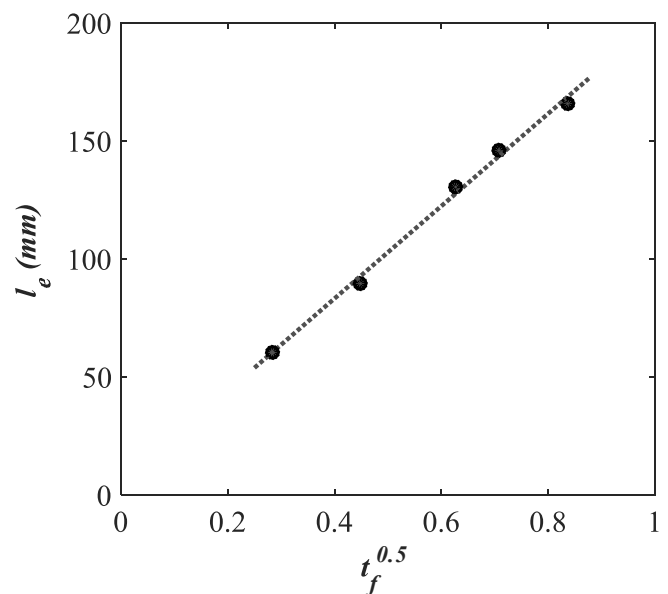

(b)

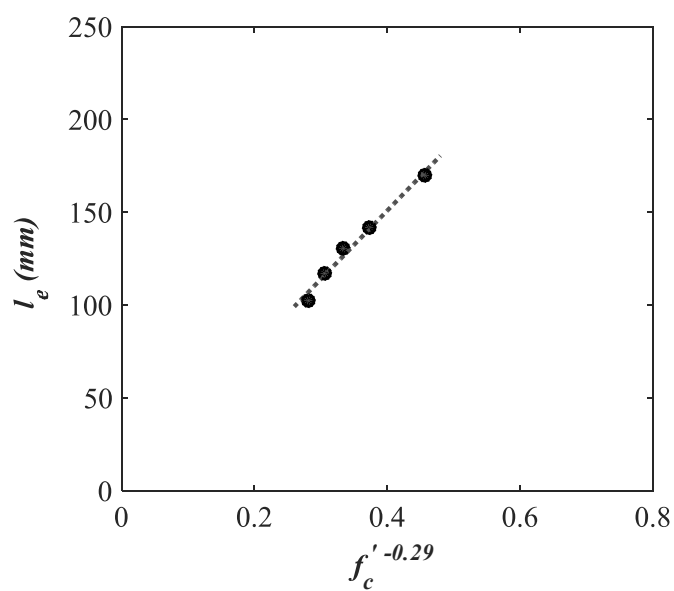

(d)

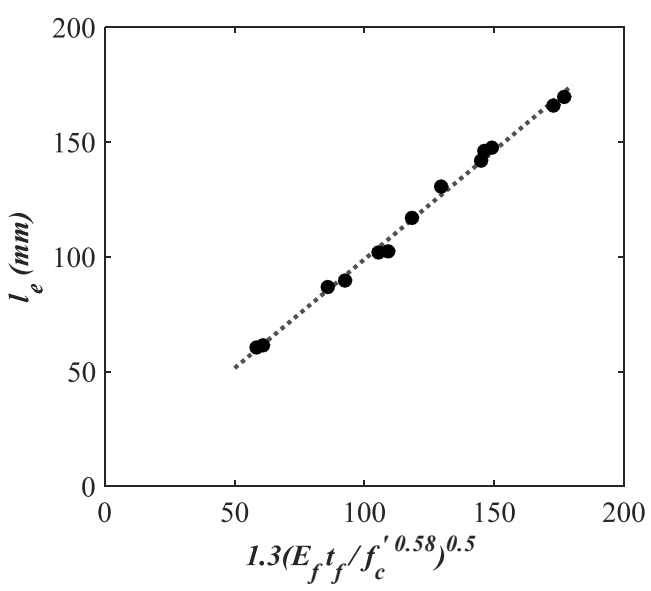

(e)

Fig. 6. Impacts of factors on the effective bond length: (a) impacts of the strip width $(75,100,125,150$ and 200 $\mathrm{mm})$; (b) impacts of the strip thickness $(0.2,0.4,0.5,0.7$ and $0.8 \mathrm{~mm})$; (c) impacts of the elastic modulus $(50,100,150,227$ and $300 \mathrm{GPa}) ;(\mathrm{d})$ impacts of the concrete strength $(15,30,44,60$ and $80 \mathrm{MPa}) ;(\mathrm{e})$ 


$$
P=P_{u}\left(2-\left(l_{f} / l_{e}\right)^{0.93}\right)\left(l_{f} / l_{e}\right)^{0.93}
$$

$$
P=P_{u}\left(2-l_{f} / l_{e}\right) l_{f} / l_{e}
$$

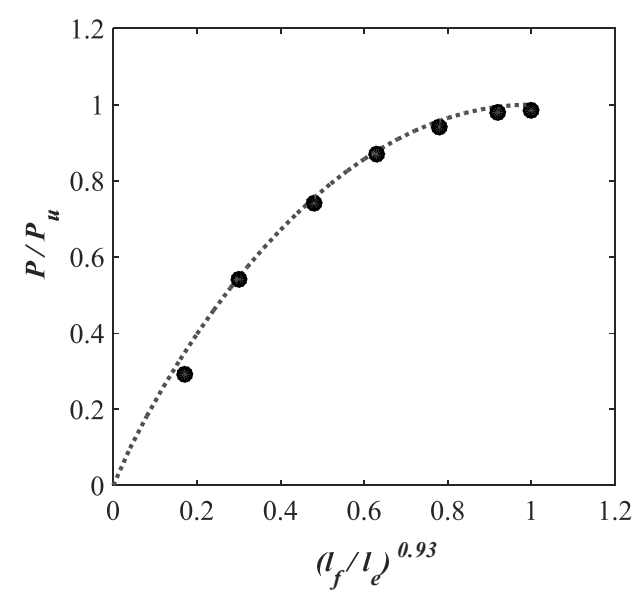

Fig. 7. Relations between $P / P_{u}$ and $l_{f} / l_{e}\left(l_{f}=20,40,60,80,100,120\right.$ and $130 \mathrm{~mm} ; l_{e}=130 \mathrm{~mm}$; $\left.P_{u}=50.22 \mathrm{kN}\right)$. strip bonded to the concrete substrate.

\subsection{Adequate bond length $l_{f} \geq l_{e}$} responses before the debondign initiation. A plateau is then added to describe the debonding propagation at the segment BC as shown in Fig. 2 (a). Finally, a parabolic part is added to describe the unloading load is less than $93 \%$ of the bond strength (Point D). 


$$
\Delta_{\text {last Pu }}=0.5\left(l_{f} / l_{e}-1\right)+s_{f} \quad l_{f} \geq l_{e}
$$

$$
\Delta_{u}=0.5\left(l_{f} / l_{e}-1\right)+1.48 s_{f} \quad l_{f} \geq l_{e}
$$

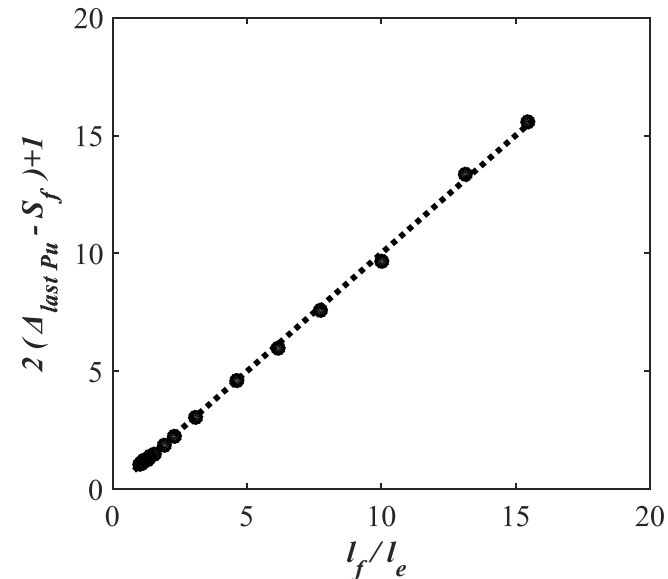

(a)

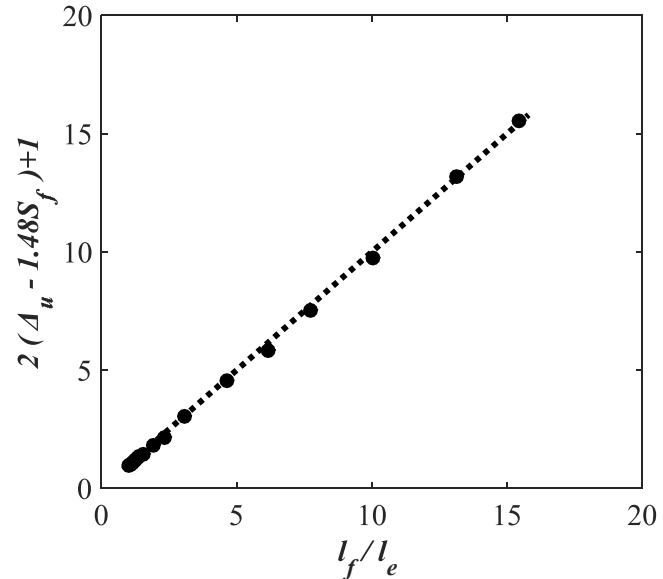

(b)

Fig. 8. Impacts of factors on the strip displacements $\left(\Delta_{\text {last } P_{u}}\right.$ and $\left.\Delta_{u}\right)$ at the (a) last $P_{u}$ and (b) $0.93 P_{u}$ at the unloading stage, respectively.

Fig. 9 illustrates the load-displacement responses for the four simulations $\left(l_{f}=150,200,250\right.$ and 300) used in Fig. 8. Based on the predictions, Eq. (16) is proposed to describe the load-displacement relations at the unloading stage as shown in Fig. 9.

$$
P=a_{1} \Delta^{2}+b_{1} \Delta+c_{1} \quad l_{f} \geq l_{e}
$$

in which

$$
a_{1}=\frac{-0.07 P_{u}}{\left(\Delta_{\text {last } P u}-\Delta_{u}\right)^{2}}
$$




$$
\begin{aligned}
& b_{1}=\frac{0.14 P_{u} \Delta_{\text {last } P u}^{2}}{\left(\Delta_{\text {last }} P u_{u}\right)^{2}} \\
& c_{1}=P_{u}-\frac{0.07 P_{u} \Delta_{\text {last } P u}^{2}}{\left(\Delta_{\text {last } P u}-\Delta_{u}\right)}
\end{aligned}
$$

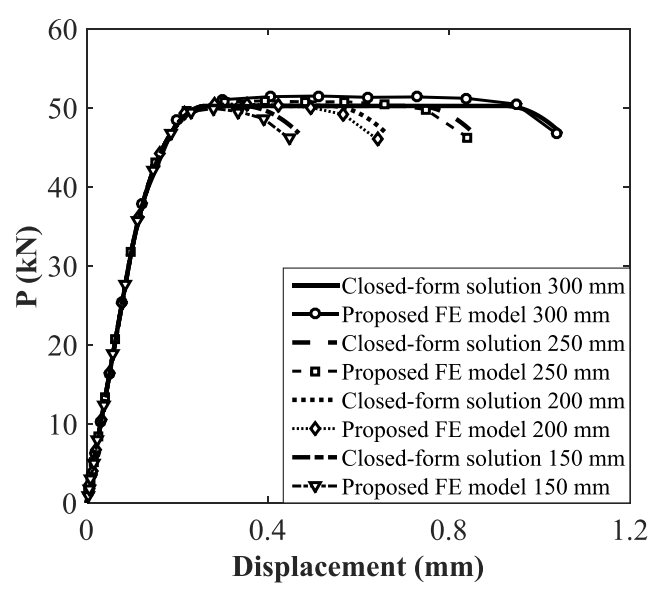

Fig. 9. Load-displacement responses obtained from the four simulations $\left(l_{f}=150,200,250\right.$ and $\left.300 \mathrm{~mm}\right)$ used in

Fig. 8 and the corresponding closed-form solutions.

\subsection{Inadequate bond length $l_{f}<l_{e}$}

For the load-displacement responses obtained from the strip with an inadequate bond length, the plateau cannot be developed as shown in Fig. 2 (b). Instead, a parabolic drop has been observed as long as the bond strength is developed. Instable predictions can be produced as the dropping load is less than 93\% of the bond strength (Point D).

In order to determine the load-displacement responses for the strip with an inadequate bond length, five simulations have been conducted. All the parameters of the five simulations are the same as specimens CNW-150-1\&2 expect the bond length varying from 40 to $120 \mathrm{~mm}$. Four points marked in Fig. 10 (a) represent the points at the origin (Point O), the softening initiation (Point A), the debonding and unloading initiation (Point B) and the debonding failure (Point D). Fig. 10 (b) illustrates the loaddisplacement responses for the five simulations $\left(l_{f}=40,60,80,100\right.$ and 200). Based on the predictions, Eq. (20) is proposed to describe the load-displacement responses for the strip with an inadequate bond length before the softening initiation (Segment OA). 


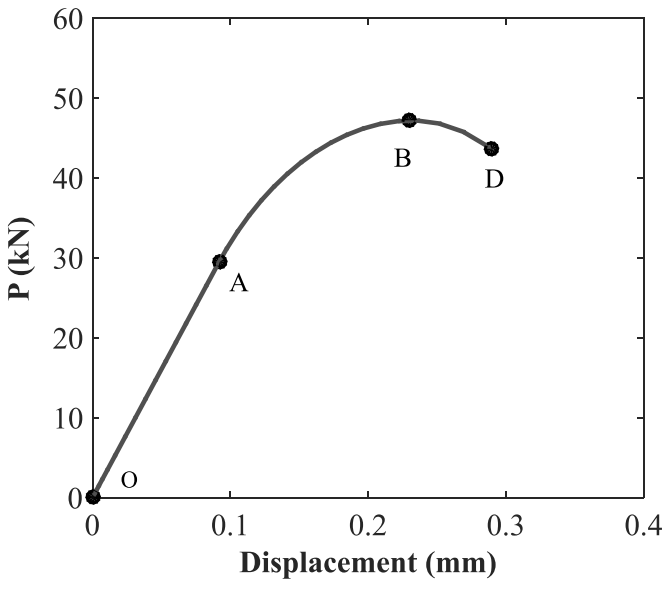

(a)

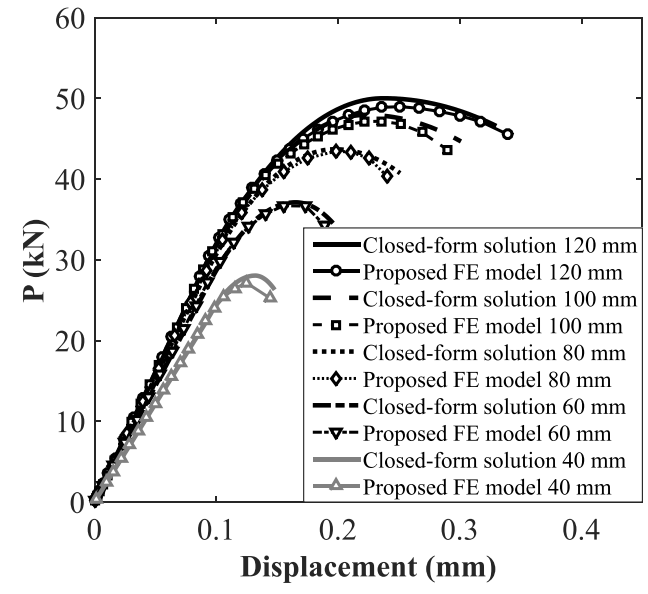

(b)

Fig. 10. Analysis of the strip displacement obtained from the strip with an inadequate bond length: (a) simulated

$$
P=\left(a_{2}-b_{2} \beta_{l}\right) \beta_{l} b_{f} \Delta \sqrt{E_{f} t_{f}} \quad l_{f}<l_{e}
$$

in which

Eq. (23) is proposed to describe the load-displacement responses at the softening stage (Segment AB).

$$
P=a_{3} \Delta^{2}+b_{3} \Delta+c_{3} \quad l_{f}<l_{e}
$$

in which

$$
a_{3}=\frac{-d^{2} P_{\text {ela_in }}^{2}}{4 s_{0}^{2}\left(P_{u \_ \text {in }}-P_{\text {ela_in }}\right)}
$$$$
b_{3}=\frac{d P_{\text {ela_in }}}{s_{0}}\left(1+\frac{d P_{\text {ela_in }}}{2\left(P_{u \_ \text {in }}-P_{\text {ela_in }}\right)}\right)
$$

$$
c_{3}=(1-d) P_{e l a \_i n}-\frac{d^{2} P_{\text {ela_in }}^{2}}{4\left(P_{u \_i n}-P_{\text {ela } \_i n}\right)}
$$

$$
d=0.87 \sqrt{\frac{1}{\beta_{l}}}
$$



$P_{u_{i} i n}$ and the corresponding displacement $\Delta_{P_{u \_i n}}$ are given by:

Eq. (31) is proposed to describe the load-displacement responses at the debonding and unloading stage (Segment BD).

The ultimate strip displacement $\Delta_{u_{-} i n}$ for the strip with an inadequate bond length is given by:

$$
\Delta_{u_{\_} i n}=\left[1.1\left(\beta_{l}^{2}-\beta_{l}\right)+1.4\right] \Delta_{P u \_i n}
$$

\section{Comparisons of analytical solutions with experimental}

\section{results and numerical predications}

The pull tests reported in the literature [42] are used to evaluate the proposed FE models and the closed-form solutions. As listed in Table 1, the reported specimens have the strip width varying from 50 to $150 \mathrm{~mm}$, the nominal strip thickness changing from 0.262 to $0.524 \mathrm{~mm}$, the elastic modulus of the FRP strip ranging from 94 to $227 \mathrm{GPa}$ and the bond length increasing from 100 to $250 \mathrm{~mm}$. Table 1 shows the predictions obtained from the proposed FE models and the analytical expressions are within a range from $90 \%$ to $105 \%$ of at least one corresponding experimental result in terms of the bond strength 
$P_{u}$ and the ultimate strip displacement $\Delta_{u}$. Inherent variability in normally identical tests, such as unpredictable crack distribution, bond condition and material variability, causes the simulations and solutions to match some experimental results with higher accuracy than others. This observation further validates the proposed FE model. The predictions obtained from the proposed FE models therefore are used to evaluate the analytical solutions when the corresponding tests are unavailable.

\subsection{Strip width}

Of particular interest in this series is to evaluate the accuracy of analytical solutions for the FRP strip with various strip widths. As shown in Fig. 11, specimen No. 1-10 listed in Table 1 are selected to evaluate the width impacts on the analytical solutions for the FRP strip with an adequate bond length. For evaluating the width impacts on the strip with an inadequate bond length, comparisons of the analytical solutions with the comparable simulations are plotted in Fig. 12. According to Eq. (11), the effective bond length is $130 \mathrm{~mm}$ for the specimen CNW 50, CNW 125 and CNW 150. The calculated value is $129 \mathrm{~mm}$ for the specimen CNW 75 and CNW 100 . 
$\begin{array}{cccccc}P_{u} & P_{u} & P_{u} & \Delta_{u} & \Delta_{u} & \Delta_{u}\end{array}$

$\begin{array}{lllll}(\mathrm{kN} \text { Test}) & (\mathrm{FEA} / \mathrm{Test}) \quad(\text { Ana./Test }) \quad(\mathrm{mm} \text { Test }) & \text { (FEA/Test) } & \text { (Ana./Test) }\end{array}$ lengt

\begin{tabular}{|c|c|c|c|c|c|c|c|c|c|c|c|c|c|}
\hline 1 & CNW-50-1 & 250 & 50 & 227 & 0.393 & 44.1 & 250 & 15.73 & 1.05 & 1.03 & 0.89 & 0.90 & 0.90 \\
\hline 2 & CNW-50-2 & 250 & 50 & 227 & 0.393 & 44.1 & 250 & 16.03 & 1.03 & 1.01 & 0.93 & 0.86 & 0.86 \\
\hline 3 & CNW-75-1 & 200 & 75 & 224 & 0.393 & 44.1 & 250 & 24.27 & 1.04 & 1.03 & 0.77 & 1.05 & 1.10 \\
\hline 4 & CNW-75-2 & 200 & 75 & 224 & 0.393 & 44.1 & 250 & 25.66 & 0.98 & 0.98 & 0.85 & 0.95 & 0.99 \\
\hline 5 & CNW-100-1 & 200 & 100 & 224 & 0.393 & 44.1 & 250 & 33.48 & 1.01 & 1.00 & 0.82 & 0.98 & 1.05 \\
\hline 6 & CNW-100-2 & 200 & 100 & 224 & 0.393 & 44.1 & 250 & 32.38 & 1.04 & 1.04 & 0.91 & 0.89 & 0.94 \\
\hline 7 & CNW-125-1 & 200 & 125 & 227 & 0.393 & 44.1 & 250 & 41.28 & 1.03 & 1.02 & 0.82 & 0.98 & 1.04 \\
\hline 8 & CNW-125-2 & 200 & 125 & 227 & 0.393 & 44.1 & 250 & 39.54 & 1.08 & 1.07 & 0.91 & 0.88 & 0.94 \\
\hline 9 & CNW-150-1 & 200 & 150 & 227 & 0.393 & 44.1 & 250 & 51.65 & 0.98 & 0.97 & 0.86 & 0.94 & 1.00 \\
\hline 10 & CNW-150-2 & 200 & 150 & 227 & 0.393 & 44.1 & 250 & 52.49 & 0.97 & 0.96 & 0.81 & 1.00 & 1.06 \\
\hline 11 & CNL-100-1 & 200 & 50 & 224 & 0.393 & 37.8 & 100 & 14.90 & 1.02 & 1.03 & 0.30 & 0.99 & 1.03 \\
\hline 12 & CNL-100-2 & 200 & 50 & 224 & 0.393 & 37.8 & 100 & 14.38 & 1.06 & 1.07 & 0.34 & 0.86 & 0.90 \\
\hline 13 & CNL-150-1 & 200 & 50 & 224 & 0.393 & 37.8 & 150 & 17.03 & 0.94 & 0.96 & 0.50 & 0.86 & 0.85 \\
\hline 14 & CNL-150-2 & 200 & 50 & 224 & 0.393 & 37.8 & 150 & 15.43 & 1.04 & 1.06 & 0.47 & 0.92 & 0.90 \\
\hline 15 & CNT-2-1 & 200 & 50 & 227 & 0.262 & 39.4 & 250 & 14.36 & 0.94 & 0.93 & 0.99 & 1.01 & 1.02 \\
\hline 16 & CNT-2-2 & 200 & 50 & 227 & 0.262 & 39.4 & 250 & 14.36 & 0.94 & 0.93 & 1.02 & 0.98 & 0.99 \\
\hline 17 & CNT-3-1 & 200 & 50 & 227 & 0.393 & 39.4 & 250 & 16.49 & 1.00 & 1.00 & 0.80 & 0.99 & 1.00 \\
\hline 18 & CNT-3-2 & 200 & 50 & 227 & 0.393 & 39.4 & 250 & 16.81 & 0.99 & 0.98 & 0.89 & 0.89 & 0.90 \\
\hline 19 & CNT-4-1 & 200 & 50 & 227 & 0.524 & 39.4 & 250 & 19.45 & 0.98 & 0.97 & 1.01 & 0.64 & 0.67 \\
\hline 20 & CNT-4-2 & 200 & 50 & 227 & 0.524 & 39.4 & 250 & 18.37 & 1.04 & 1.03 & 0.67 & 0.97 & 1.00 \\
\hline 21 & CNE-94-1 & 200 & 50 & 94 & 0.51 & 39.4 & 250 & 13.03 & 0.94 & 0.92 & 1.23 & 0.93 & 0.92 \\
\hline 22 & CNE-94-2 & 200 & 50 & 94 & 0.51 & 39.4 & 250 & 13.80 & 0.89 & 0.87 & 1.33 & 0.86 & 0.86 \\
\hline
\end{tabular}

312

Table 1 Comparisons of experimental results with numerical predictions and analytical solutions. 


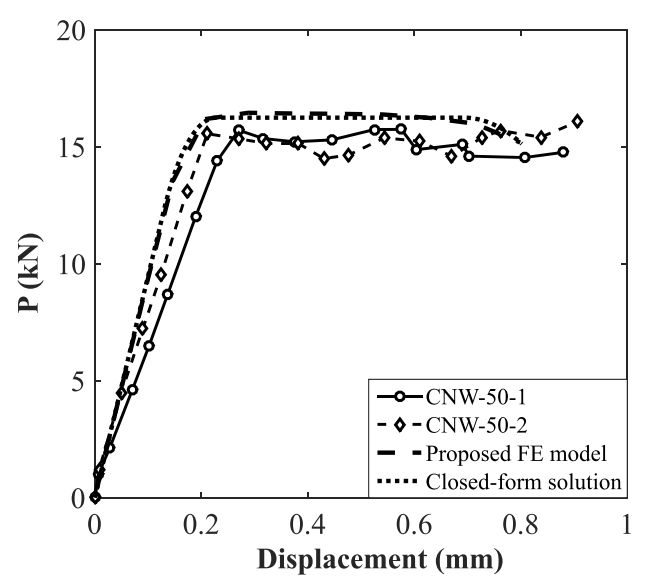

(a)

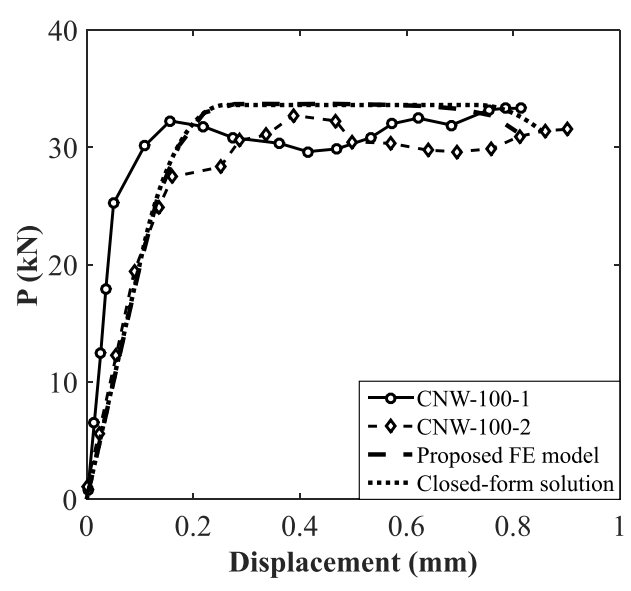

(c)

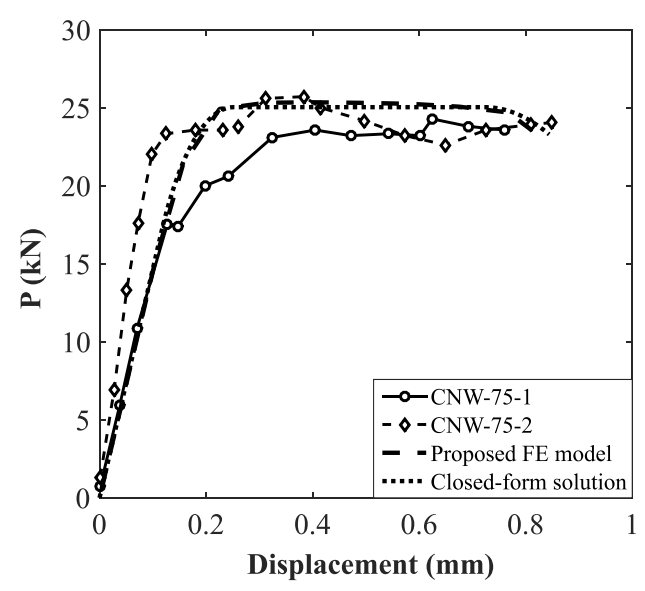

(b)

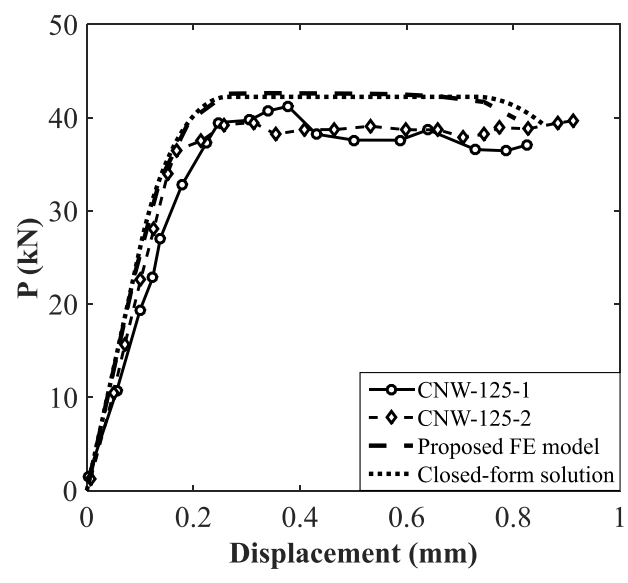

(d)

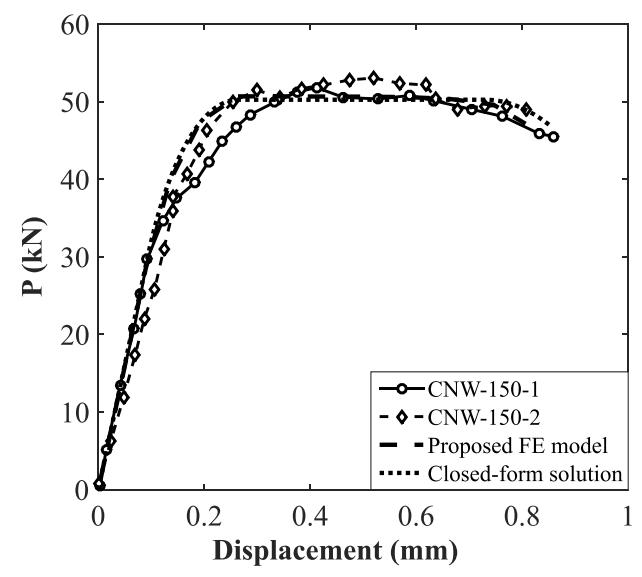

Fig. 11. Comparisons of load-displacment responses between the numerical predictions and the corresponding 
As shown in Fig. 11, all numerical simulations and analytical solutions not only capture the trend of increased the bond strength with increasing strip width but also agree well with at least one directly corresponding test in terms of the load-displacement shape, the bond strength and the ultimate strip displacement. The predicted bond strengths obtained from the proposed FE models and the analytical expressions are within a range from $96 \%$ to $108 \%$ of the experimental measurements. The largest differences in terms of the ultimate strip displacement have been found in Fig. 11 (a). Nevertheless, the ultimate displacements obtained from the analytical solution and the proposed FE model are $90 \%$ of that measured from specimen CNW-50-1. It suggests that reasonable predictions for the strip having an adequate bond length and a width ranging from 50 to $150 \mathrm{~mm}$ can be achieved by the analytical solutions and the proposed FE models. are the same as the corresponding specimen listed in Table 1 except the bond length varying from 40 to $120 \mathrm{~mm}$. It can be found that the analytical solutions give results in close agreement with the predictions $102 \%$ of the simulated ultimate strip displacement. It further validates the analytical solutions on predicting the load-displacement responses for the strip with various strip widths. 


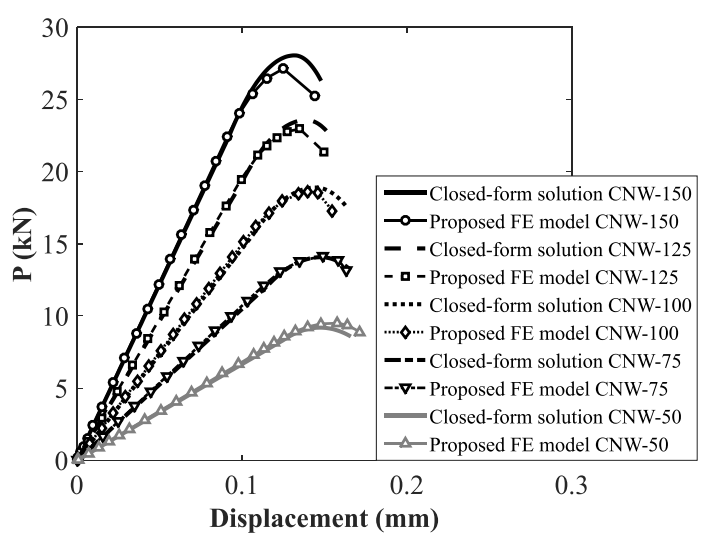

(a)

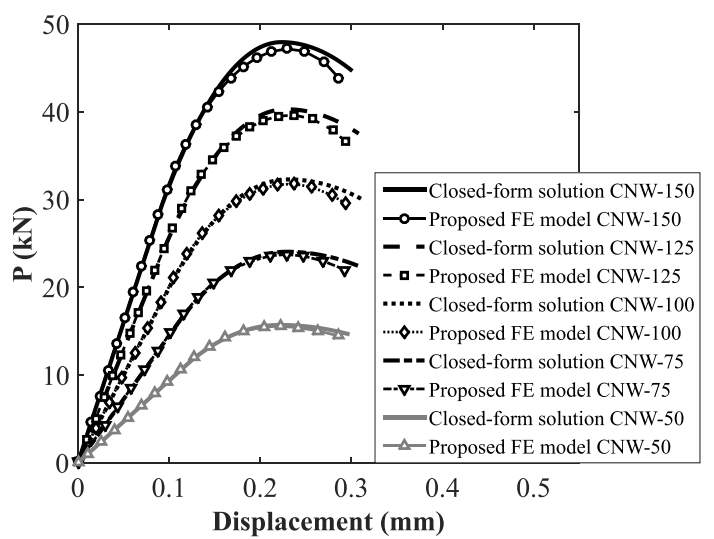

(c)

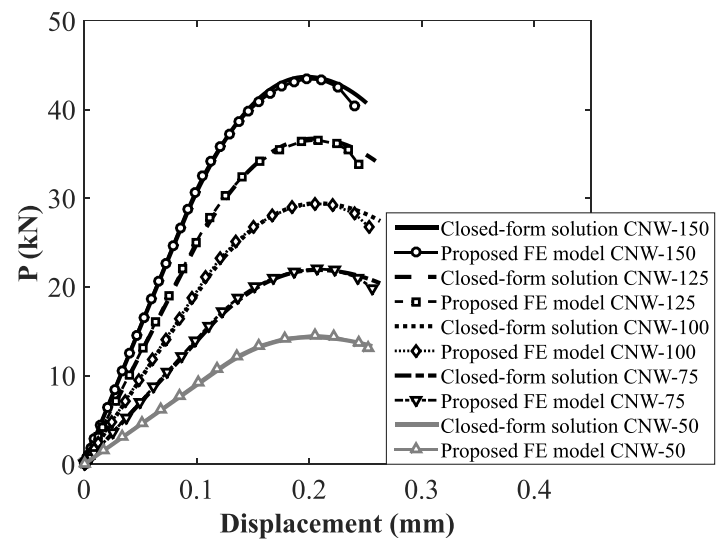

(b)

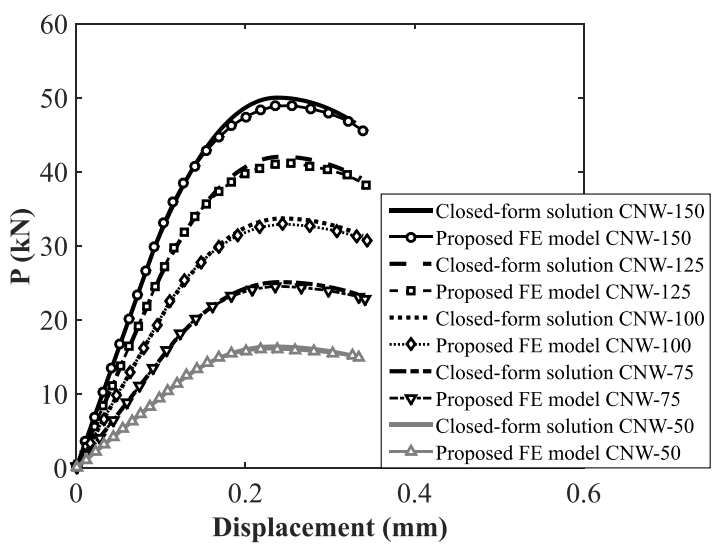

(d)

Fig. 12. Comparisons of load-displacment responses between the analytical solutions and the numerical predictions obtained from the simulations having various widths and inadequate bond lengths : (a) $l_{f}=$ $40 \mathrm{~mm},(\mathrm{~b}) l_{f}=80 \mathrm{~mm}$, (c) $l_{f}=100 \mathrm{~mm}$ and (d) $l_{f}=120 \mathrm{~mm}$.

The proposed FE models and the analytical solutions have been previously validated by the strips with a $250 \mathrm{~mm}$ bond length. In this section, specimen No. 11-14 listed in Table 1 are selected to further evaluate the bond length impacts on the proposed FE models and the analytical solutions. The reported bond length for specimen No. 11-12 and No. 13-14 are 100 and 150 mm, respectively. Based on Eq. (11), the effective bond length of the selected specimens is $135 \mathrm{~mm}$. With an inadequate bond length, few plateaus have been found from the experimental, numerical and analytical relations as shown in Fig. 13 
analytical solution with an adequate bond length as shown in Fig. 13 (b). Fig. 13 also illustrates that both the numerical predictions and the analytical solutions are in close agreement with the experimental results in terms of the bond strength, the ultimate strip displacement and the overall load-displacement shape. comparisons have been conducted and shown in Fig. 14. All parameters used in the simulations and the analytical solutions are the same as the specimen No. 11-12 except the bond length varying from 40 to trend of increased the bond strength with increasing the bond length for the strip with an inadequate bond length. A further increase of the bond length beyond the effective bond length (from 300 to $4500 \mathrm{~mm}$ ) results in few increases on the bond length but improves the ductility of the debonding process as shown ranging from 40 to $4500 \mathrm{~mm}$.

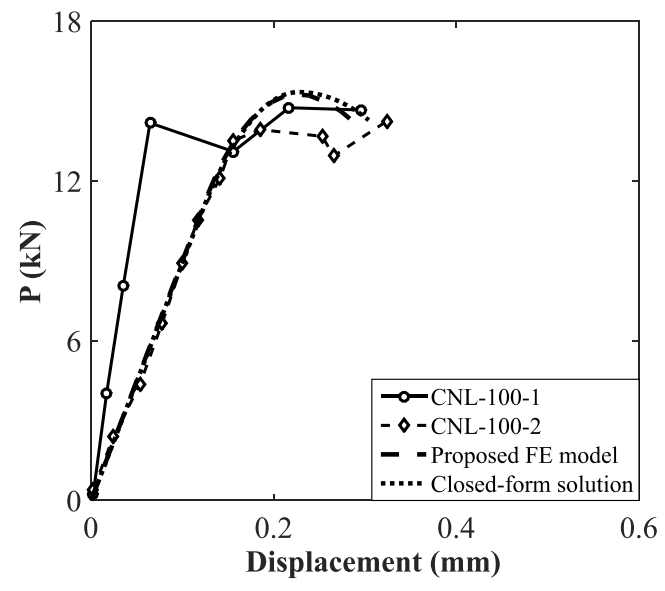

(a)

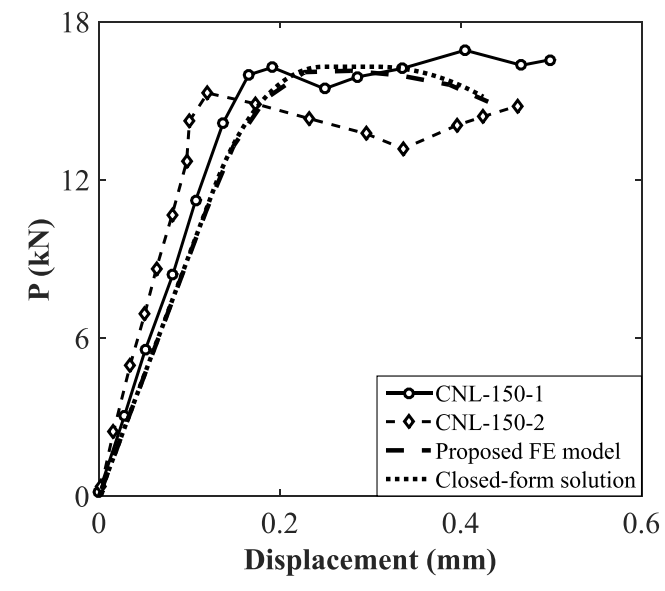

(b)

Fig. 13. Comparisons of load-displacment responses between the numerical predictions and the corresponding 


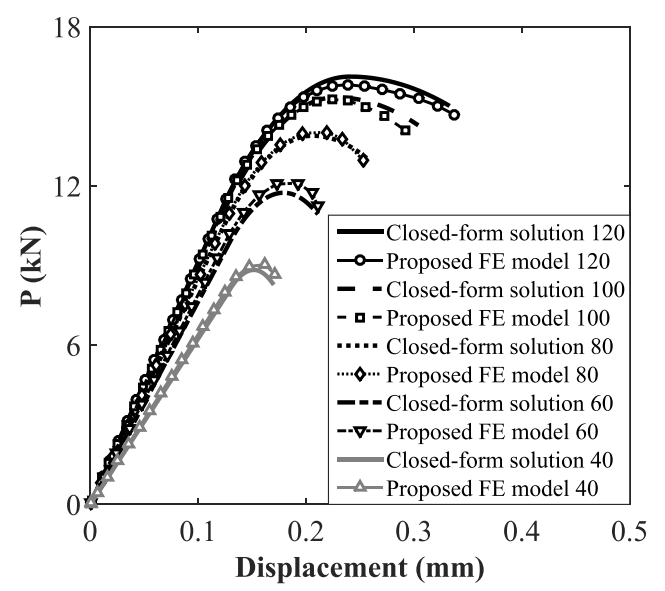

(a)

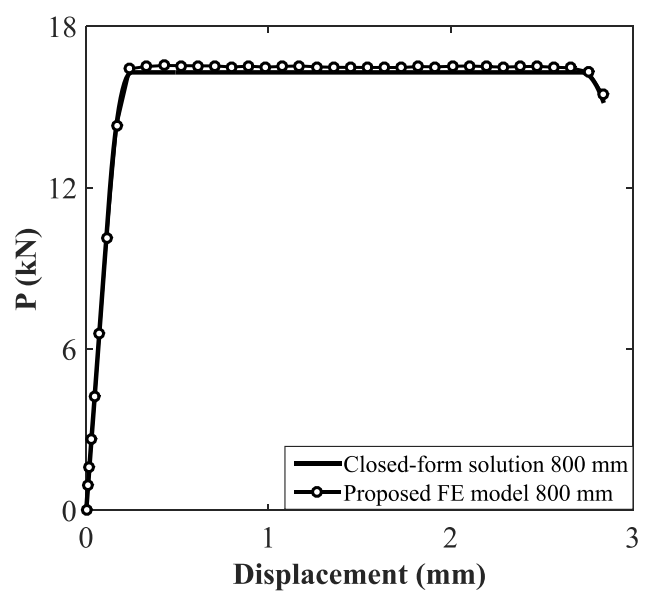

(c)

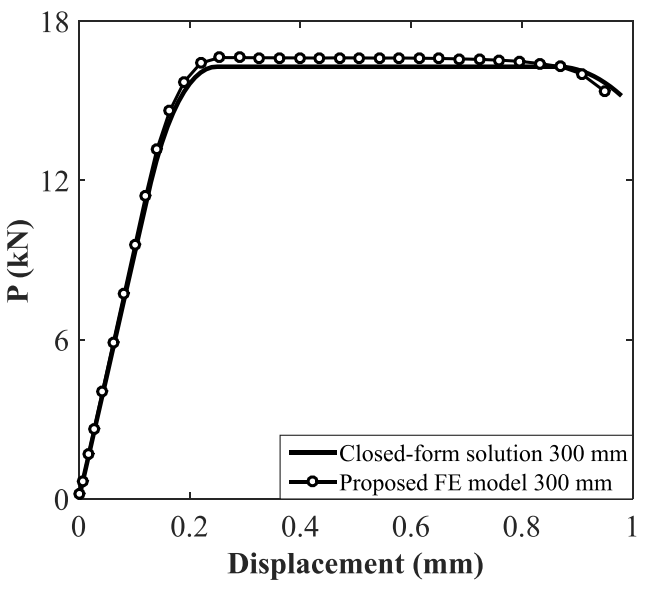

(b)

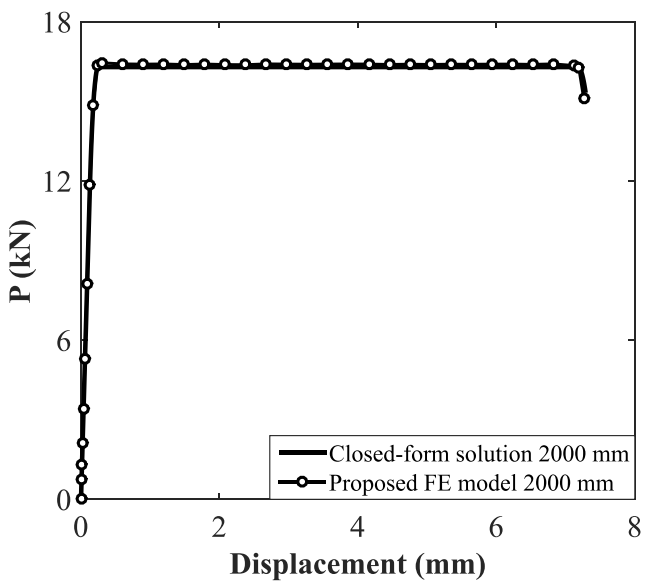

(d)

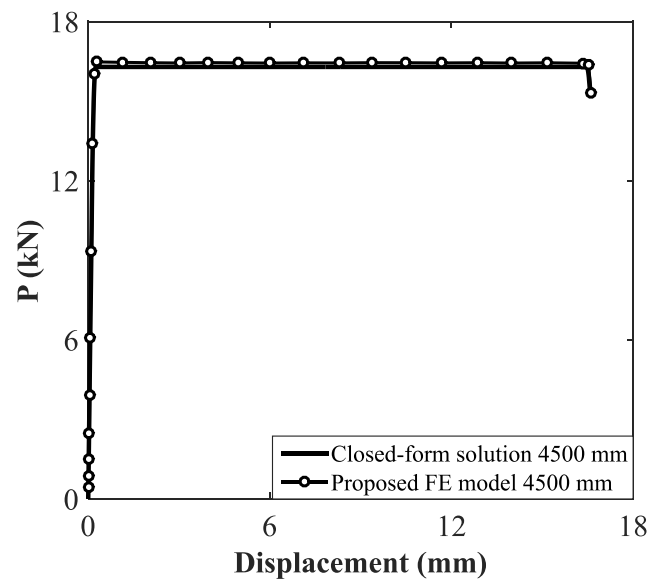

Fig. 14. Comparisons of load-displacment responses between the analytical solutions and the numerical 
In this section, specimen No. $15-22$ listed in Table 1 are selected to evaluate the impacts of the thickness and the elastic modulus on the analytical solutions and the proposed FE models. Fig. 15 illustrates that the analytical expressions and the numerical simulations predict the load-displacement responses in close agreement with the experimental results. The trend of increased the bond strength and reduced the debonding ductility with increasing the strip thickness (from 0.262 to $0.524 \mathrm{~mm}$ ) has been well captured by the analytical solutions and the numerical simulations as shown in Fig. 15 (a)-(c) and listed in Table 1. In Fig 15 (d), all parameters of the specimen No. 21-22 are the same as that of the specimen No. 19-20 except the elastic modulus increasing from 94 to $227 \mathrm{GPa}$ and the thickness slightly varying from 0.51 to $0.524 \mathrm{~mm}$. As shown in Fig. 15 (c)-(d), both the analytical solutions and numerical simulations capture the trend of increased the debonding ductility and reduced the bond strength with reducing the elastic modulus from 227 to $94 \mathrm{GPa}$. It suggests that the analytical solutions and the proposed FE models can reliably predict the load-displacement responses for the strip with thickness ranging from 0.262 to $0.524 \mathrm{~mm}$ and elastic modulus varying from 94 to $227 \mathrm{GPa}$. 


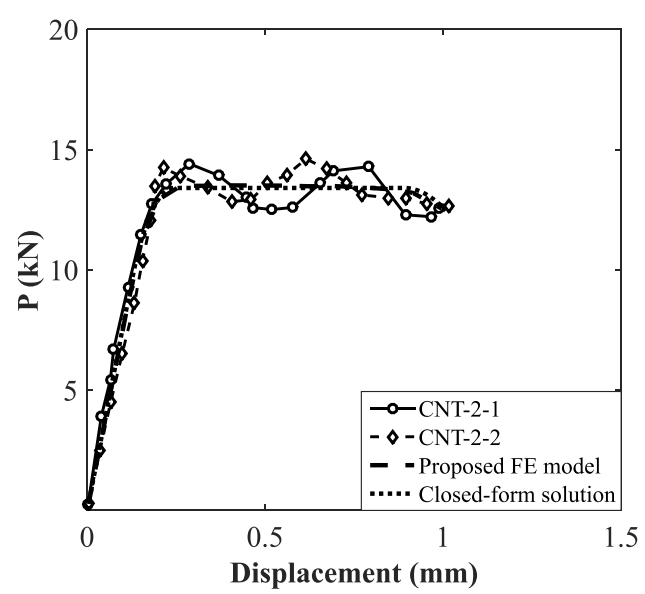

(a)

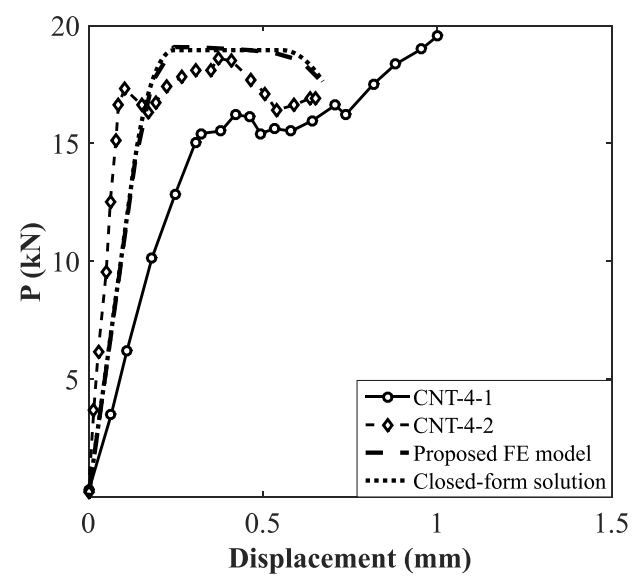

(c)

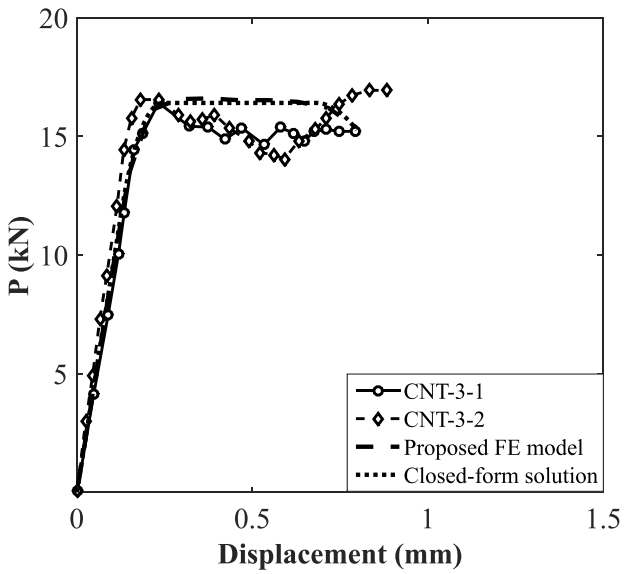

(b)

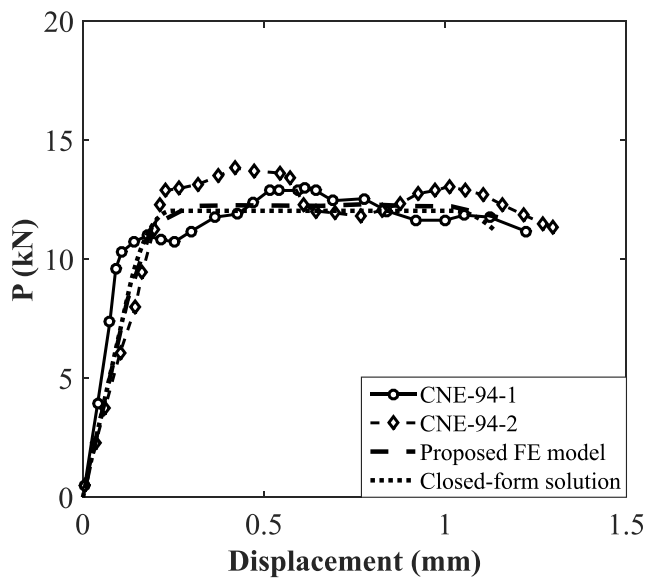

(d)

Fig. 15. Comparisons of load-displacment responses between the analytical solutions and the numerical predictions obtained from the simulations having various thickensses and elastic modulus of the FRP strip: (a) $t_{f}=0.262 \mathrm{~mm} \mathrm{\&} E_{f}=227 \mathrm{GPa}$ (b) $t_{f}=0.393 \mathrm{~mm} \mathrm{\&} E_{f}=227 \mathrm{GPa}$, (c) $t_{f}=0.524 \mathrm{~mm} \mathrm{\&}$ $E_{f}=227 \mathrm{GPa}$ and (d) $t_{f}=0.51 \mathrm{~mm} \& E_{f}=94 \mathrm{GPa}$. 


\section{Conclusion}

This paper has proposed a set of FE models to study the entire debonding propagation process for the strip with various strip widths, bond lengths, thicknesses and elastic modulus. The assessment of the FE models has been conducted using the test results of 22 pull specimens. Based on the predictions obtained from the proposed FE models, closed-form expressions have been developed to predict the loaddisplacement responses. The analytical solutions have been evaluated against the experimental results and the comparably simulations to draw the following conclusions:

1. All simulations performed well and estimated the load-displacement responses of pull tests with high accuracy. Within a size range from 0.1 to $5 \mathrm{~mm}$, the proposed FE models showed limited sensitivity to the element size. In addition, the simulations accurately captured the impacts of the strip width, the bond length, the thickness and the elastic modulus on the bond behavior.

2. Based on the numerical predictions, the analytical expressions have been developed to describe the load-displacement behavior of the strip with various strip widths, bond lengths, thicknesses and elastic modulus. The load-displacement behavior of the strip with an adequate bond length featured four stages, i. e. the elastic stage, the softening stage, the plateau stage and the unloading stage. For the strip with an inadequate bond length, the load-displacement behavior featured the same three stages without the plateau stage. The function of the effective bond length has been also proposed to determine whether a bond length was adequate or not.

3. The analytical solutions well captured the trend of (1) increased the bond strength with increasing strip width; (2) increased the bond strength with increasing bond length for the strip using an inadequate bond length or increased the debonding ductility instead of the bond strength with increasing bond length for the strip using an adequate bond length, and (3) increased the 
debonding ductility and reduced the bond strength with increasing the thickness and elastic modulus of the strip.

4. Overall, the analytical solutions have been shown in close agreement with experimental results and numerical predictions. The analytical expressions therefore can be used to determine the load-displacement behavior of the FRP strip bonded to the concrete substrate. 


\section{Acknowledgements}

The support of the National Natural Science Foundation of China [grant numbers 51608244], the

Fundamental Research Funds for the Central University [grant numbers lzujbky-2016-k14], the Key

Laboratory of Ministry of Education for Mechanics on Western Disaster and Environment, and the

School of Civil Engineering and Mechanics at Lanzhou University are gratefully acknowledged. The contents of this paper reflect the views of the authors, who are responsible for the facts and the accuracy of the data presented herein. The contents do not necessarily reflect the official view or policies of the sponsoring organizations. This paper does not constitute a standard, specification, or regulation. 


\section{References}

[1] W. Sun, J.O. Jirsa, W.M. Ghannoum, Behavior of anchored carbon fiber reinforced polymer strips used for strengthening concrete structures, ACI Mater. J. 113 (2) (2016) 163-172.

[2] S.A. Hadigheh, R.J. Gravina, S. Setunge, Identification of the interfacial fracture mechanism in the FRP laminated substrates using a modified single lap shear test set-up, Eng. Fract. Mech. 134 (2015) $317-329$.

[3] T. D'Antino, C. Pellegrino, Bond between FRP composites and concrete: Assessment of design procedures and analytical models, Compos. B 60 (2014) 440-456.

[4] C. Carloni, K.V. Subramaniam, Investigation of sub-critical fatigue crack growth in FRP/concrete cohesive interface using digital image analysis, Compos. B 51(8) (2013) 35-43.

[5] M.H. Al-Allaf, L. Weekes, L. Augusthus-Nelson, P. Leach, An experimental investigation into the bond-slip behaviour between CFRP composite and lightweight concrete, Constr. Build. Mater. 113 (2016) 15-27.

[6] B. Zidani, K. Belakhdar, A. Tounsi, E.A.A. Bedia, Finite element analysis of initially damaged beams repaired with FRP plates, J. Compos. Constr. 134 (2015) 429-439.

[7] E. Dehghani, F. Daneshjoo, A.A. Aghakouchak, N. Khaji, A new bond-slip model for adhesive in CFRP-steel composite systems, Eng. Struct. 34 (1) (2013) 447-454.

[8] W. Sun, W.M. Ghannoum, Modeling of anchored CFRP strips bonded to concrete, Constr. Build. Mater. 85 (2015) 144-156.

[9] S. Orton, J.O. Jirsa, O. Bayrak, Carbon fiber-reinforced polymer for continuity in existing reinforced concrete buildings vulnerable to collapse, ACI Struct. J. 106 (5) (2009) 608-616.

[10] Y. Kim, K.T. Quinn, C.N. Satrom, W.M. Ghannoum, J.O. Jirsa, Shear strengthening RC T-beams 
using CFRP laminates and anchors, ACI Special Publication SP-275 (36) (2011) 1-18.

[11] J.F. Bonacci, M. Maalej, Behavioral trends of RC beams strengthened with externally bonded FRP.

J. Compos. Constr. 5 (2) (2001) 102-113.

[12] L.T. Pham, Development of a quality control test for carbon fiber reinforced polymer anchors, Master thesis, The University of Texas at Austin, America, 2009.

[13] G. Huaco, Quality control test for carbon fiber reinforced polymer (CFRP) anchors for rehabilitation. Master thesis, The University of Texas at Austin, America, 2009.

[14] F.J. Vecchio, F. Bucci, Analysis of repaired reinforced concrete structures, J. Struct. Eng. 125 (6) (1999) 644-652.

[15] J.F. Chen, J.G. Teng, Anchorage strength models for FRP and steel plates bonded to concrete, J. Struct. Eng. 127 (7) (2001) 784-791.

[16] J. Yao, J.G. Teng, J.F. Chen, Experimental study on FRP-to-concrete bonded joints, Compos. B 36 (2005) 99-113.

[17] M.J. Chajes, W.W.J. Finch, T.F. Januszka, T.A.J. Thonson, Bond and force transfer of composite material plates bonded to concrete, ACI Struct. J. 93 (2) (1996) 208-17.

[18] C. Mazzotti, M. Savoia, B. Ferracuti, An experimental study on delamination of FRP plates bonded to concrete, Constr. Build. Mater. 22 (7) (2008) 1409-1421.

[19] K. Nakaba, T. Kanakubo, T. Furuta, H. Yoshizawa, Bond behavior between fiber-reinforced polymer laminates and concrete, ACI Struct. J. 98 (3) (2002) 359-367.

[20] U. Neubauer, F.S. Rostasy, Design aspects of concrete structures strengthened with externally bonded CFRP plates, In: Proceedings of 7th international conference on structural faults andrepair, Edinburgh (Scotland), July, 1997, pp.109-118. 
[21] G. Monti, M. Renzelli, P. Luciani, FRP adhesion in uncracked and cracked concrete zones, In: Proceedings of 6th international symposium on FRP reinforcement for concrete structures, Singapore,June, 2003, pp.183-192.

[22] J.G. Dai, T. Ueda, Local bond stress slip relations for FRP sheets concrete interfaces, In: Proceedings

of 6th international symposium on FRP reinforcement for concrete structures, Singapore, June, 2003. pp.143-152.

[23] J.G. Dai, T. Ueda, Y. Sato, Development of the nonlinear bond stress-slip model of fiber reinforced plastics sheet-concrete interfaces with a simple method, J. Compos. Constr. 9 (1) (2005) 52-62.

[24] J. Yao, J.G. Teng, J.F. Chen, Experimental study on FRP-to concrete bonded joints, Compos. B 36 (2005) 99-113.

[25] H.W. Zhang, Influence of FRP anchors on FRP-to-concrete bonder interfaces, Ph.D. Dissertation, The University of Hong Kong, China, 2013.

[26] C. Mazzotti, M. Savoia, B. Ferracuti,A new single-shear set-up for stable debonding of FRP-concrete joints, Constr. Build. Mater. 23 (2009) 1529-1537.

[27] X.Z. Lu, L.P. Ye, J.G. Teng, J.J. Jiang, Meso-scale finite element model for FRP sheets/plates bonded to concrete, Eng. Struct. 27 (4) (2005) 564-575.

[28] X.Z. Lu, J.G. Teng, L.P. Ye, J.J. Jiang, Bond-slip models for FRP sheets/plates bonded to concrete, Eng. Struct. 27 (6) (2005) 920-937.

[29] J.F. Chen, W.K. Pan, Three dimensional stress distribution in FRP-to-concrete bond test specimens, Constr. Build. Mater. 20 (2006) 46-58.

[30] T. Xu, Z.J. He, C.A. Tang, W.C. Zhu, P.G. Ranjith, Finite element analysis of width effect in interface debonding of FRP plate bonded to concrete, Finite Elements in Analysis and Design 93 
(2014) 30-41.

[31] Y. Tao, J.F. Chen, ASCE M., Concrete damage plasticity model for modeling FRP-to-concrete bond behavior, J. Compos. Constr. 19 (1) (2015) 04014026.

[32] J.P. Lin, Y.F. Wu, Numerical analysis of interfacial bond behavior of externally bonded FRP-toconcrete joints, J. Compos. Constr. 20 (5) (2016) 04016028.

[33] H.B. Pham, R. Al-Mahaidi, V. Saouma, Modelling of CFRP-concrete bond using smeared and discrete cracks, Compos. Struct. 75(1-4) (2006) 145-150.

[34] U. Neubauer, F.S. Rostasy, Bond failure of concrete fiber reinforced polymer plates at inclined cracks-experiments and fracture mechanics model, In: Proc. of 4th international symposium on fiber reinforced polymer reinforcement for reinforced concrete structures, SP-188. Farmington Hills (MI): ACI, 1999, pp. 369-382.

[35] R. Kotynia, H. A. Baky, U.A. Ebead, K.W. Neale, Flexural strengthening of RC beams with externally bonded CFRP systems: test results and 3D nonlinear FE analysis, J. Compos. Constr. 12 (2) (2008) 190-201.

[36] X.Z. Lu, J.G. Teng, L.P. Ye, J.J. Jiang, Intermediate crack debonding in FRP-strengthened RC beams: FE analysis and strength model, J. Compos. Constr. 11 (2) (2007) 161-174.

[37] H. Yuan, J.G. Teng, R. Seracino, Z.S. Wu, J. Yao, Full-range behavior of FRP-to-concrete bonded joints, Eng. Struct. 26 (2004) 553-565.

[38] J.L. Pan, Y.F. Wu, Analytical modeling of bond behavior between FRP plate and concrete, Compos. B Eng. 61 (2014) 17-25.

[39] W. Sun, X. Peng, Y. Yu, Development of a simplified bond model used for simulating FRP strips bonded to concrete, Compos. Struct. (submitted). 
[40] E. Dehghani, F. Daneshjoo, A.A. Aghakouchak, N. Khaji, A new bond-slip model for adhesive in CFRP-steel composite systems, Eng. Struct. 34 (1) (2012) 447-454.

[41] SAS, ANSYS 12.1 Finite element analysis system, SAS IP, Inc 2009.

[42] H.W. Zhang, S.T. Simth, Fiber-reinforced polymer (FRP)-to-concrete joints anchored with FRP anchors: test and experimental trands, Can. J. Civ. Eng. 40 (11) (2013) 1103-1116.

[43] American Concrete Institute (ACI), Guide for the design and construction of externally bonded FRP systems for strengthening of concrete structure, ACI 440.2R-08, Farmington Hill, Michigan, 2008.

[44] FIB Bulletin 14, Externally bonded FRP reinforcement for RC structures, Lausanne, Switzerland, 2001.

[45] A. Khalifa, W.J. Gold, A. Nanni, A. Abdel, Contribution of externally bonded FRP to shear capacity of RC flexural members, J. Compos. Constr. 2 (4) (1998) 195-202.

[46] Japan Concrete Institute (JCI), Technical report of technical committee on retrofit technology. In: Proceedings of the international symposium on latest achievement of technology and research on retrofitting concrete structures, Japan, Kyoto, 2003.

[47] U.S. Camli, B. Binici, Strength of carbon fiber reinforced polymers bonded to concrete and masonry, Constr. Build. Mater. 21 (2007) 1431-1446. 